\title{
La música abordada como una práctica: una relectura del concepto de intertextualidad
}

\author{
Music as Practice: a Reinterpretation \\ of the Concept of Intertextuality
}

El concepto de intertextualidad, acuñado por Julia Kristeva (1967) a partir de la idea de dialogismo de Mijaíl Bajtín, ha sido estudiado por diferentes musicólogos, como Robert Hatten (1995), Omar Corrado (1992), Rubén López Cano (2005, 2007 y 2018) y Mark Spicer (2009). Desde diversas perspectivas, estos trabajos se refieren a la relación "textual" en la música. En este trabajo propongo otro tipo de relaciones musicales intertextuales, a partir de la idea de John Fiske menos restrictiva que las anteriores, que permite ampliar el estudio de otros elementos de la práctica musical que no conforman el "texto" musical. Desde este nuevo punto de vista musicológico se analizan algunas obras de Les Luthiers y La Banda Elástica. El primero es un grupo humorístico-musical argentino que lleva 50 años de actividad ininterrumpida. El segundo fue un grupo de carácter instrumental que reunió ocho músicos del ambiente jazzístico argentino entre 1988 y 1993.

Palabras clave: Les Luthiers, La Banda Elástica, Intertextualidad, Instrumentos informales, Argentina, fusión.

The concept of intertextuality, coined by Julia Kristeva (1967) from Mijaíl Bajtin's idea of dialogism, has been studied by various musicologists including Robert Hatten (1995), Omar Corrado (1992), Rubén López Cano (2005, 2007 and 2018) and Mark Spicer (2009). These studies refer to the "textual" connection in music from different perspectives. This article proposes a different type of intertextual musical connections, based on John Fiske's less restrictive idea, which embraces the study of other elements of musical practice that do not form part of the musical "text". This new musicological standpoint is used to analyse several works by Les Luthiers and La Banda Elástica. The former is an Argentinian musical-comedy troupe that has been performing uninterruptedly for over 50 years. The latter was an instrumental ensemble group made up of eight musicians from the Argentinian jazz scene between 1988 and 1993. fusion.

Keywords: Les Luthiers, La Banda Elástica, intertextuality, informal instruments, Argentina,

Este trabajo expone una revisión del modo en que ha sido adoptado el concepto de intertextualidad en los estudios de musicología y propone una relectura a partir de una concepción de la música que prioriza su condición 
de práctica comunicativa. Para ello repaso los orígenes de este concepto en el ámbito de la literatura, acuñado por Julia Kristeva ${ }^{1}$, a partir de la idea de dialogismo bajtiniano. Al mismo tiempo, reviso la propuesta teórica más restrictiva de Gérard Genette ${ }^{2}$. Luego, en el campo de la música, considero la perspectiva de Robert Hatten ${ }^{3}$, quien sostiene que es posible aplicar la noción de intertextualidad a cualquier tipo de texto. A esta se suman los aportes de Omar Corrado ${ }^{4}$, Rubén López Cano ${ }^{5}$ y Mark Spicer ${ }^{6}$, que enriquecieron el debate 7 . Por último, y para argumentar a favor de una conceptualización menos restringida, recurro al trabajo de John Fiske ${ }^{8}$ en el área de los estudios de comunicación, que ofrece una noción más abarcadora de intertextualidad.

Esta propuesta es ilustrada con obras de dos grupos argentinos consagrados. El primero, Les Luthiers, es un grupo humorístico-musical que ha parodiado escenas de la música "académica" y la "popular" y aún se encuentra en actividad en América Latina y España. El segundo, La Banda Elástica, fue un grupo de carácter instrumental que reunió músicos del ambiente jazzístico de Buenos Aires entre 1988 y 1993.

${ }^{1}$ Julia Kristeva: "Bajtín, la palabra, el diálogo y la novela", Intertextualité. Francia en el origen de un término y el desarrollo de un concepto, La Habana, Casa las Américas, 1997 [1967], pp. 1-24.

${ }^{2}$ Gérard Genette: Palimpsestos. La literatura en segundo grado, Madrid, Taurus, 1989.

${ }^{3}$ Robert Hatten: "El puesto de la intertextualidad en los estudios musicales", Criterios, 32, 1994 [1985], pp. 211-219.

${ }^{4}$ Omar Corrado: "Posibilidades intertextuales del dispositivo musical", Migraciones de sentidos: tres enfoques sobre lo intertextual, Raquel Kreichman, Omar Corrado, Jorge Malachevski (eds.), Buenos Aires, Centro de Publicaciones UNL, 1992, pp. 33-51.

${ }^{5}$ Rubén López Cano: "Más allá de la intertextualidad. Tópicos musicales, esquemas narrativos, ironía y cinismo en la hibridación musical de la era global", Nassarre. Revista Aragonesa de Musicología, 21, 1, 2005. Véase también R. López Cano: "Música e intertextualitad", Pauta. Cuadernos de Teoría y Crítica Musical, 104, 2007, pp. 30-36.

${ }^{6}$ Mark Spicer: "Strategic Intertextuality in Three of John Lennon's Late Beatles Songs", Special Feature-A Music-Theoretical Matrix: Essays In Honor Of Allen Forte (Part I), Gamut, 2, 1, 2009 (http://trace. tennessee.edu/gamut/vol2/issl/, consulta 1-2-2010).

${ }^{7}$ Otros musicólogos han incursionado en la noción de intertextualidad aunque de una manera más tangencial, para dar cuenta de las diferentes mediaciones entre el autor de una obra y su audiencia: Richard Middleton: "Work-in-(g) Practice: Configuration of the Popular Music Intertext", The Musical Work; Reality or Invention?, Michael Talbot (ed.), Liverpool, Liverpool University Press, pp. 59-87. Serge Lacasse: "Intertextuality and Hypertextuality in Recorded Popular Music", The Musical Work; Reality or Invention?, Michael Talbot (ed.), Liverpool, Liverpool University Press, pp. 35-58. S. Lacasse: "Intertextuality as a Tool for the Analysis of Popular Music: Gerard Genette and the Recorded Palimpsest", paper presented in the 12th conference of IASPM, Montreal, 2003. Kevin Korsyn: "Beyond Priviliged Contexts: Intertextuality, Influence, and Dialogue", Rethinking Music, Nicholas Cook, Mark Everist (eds.), Oxford, Oxford University Press, 2001, pp. 55-72.

${ }^{8}$ John Fiske: Television Culture, Londres, Routledge, 1987. 


\section{La intertextualidad en sus orígenes}

El concepto de intertextualidad fue propuesto por Julia Kristeva a partir del planteo teórico de Mijaíl Bajtín, para dar cuenta de cómo se sitúa el texto en la historia y en la sociedad:

[...] Bajtín es uno de los primeros en sustituir la segmentación estática de los textos por un modelo en que la estructura literaria no es, sino que se elabora con respecto a otra estructura. Esta dinamización del estructuralismo solo es posible a partir de una concepción según la cual la "palabra literaria" no es un punto (en sentido fijo), sino un cruce de superficies textuales, un diálogo de varias escrituras: del escritor, del destinatario (o del personaje), del contexto cultural actual o anterior?

A partir de estos supuestos, el funcionamiento poético del lenguaje, según la autora, adquiere una dimensión tridimensional compuesta por el sujeto de la escritura, el destinatario y otros textos. Esta tríada establece, a su vez, dos tipos de estatus de la palabra. Uno, en un eje horizontal, pertenece simultáneamente al sujeto de la escritura y al destinatario; otro, en un eje vertical, está orientado a un corpus literario anterior o sincrónico. Similarmente al planteo que estaba desarrollando Bajtín en ese momento ${ }^{10}$, según el cual "todo texto se construye como mosaico de citas, todo texto es absorción y transformación de otro texto" 11 , Kristeva instala el concepto de intertextualidad. Este incorpora las ideas de dialogismo y ambivalencia bajtinianos. Por "dialogismo" entiende la palabra como subjetividad y como comunicatividad a la vez. Para Bajtín, "el diálogo no es solo el lenguaje asumido por un sujeto: es una escritura en la que se lee al otro" 12 . La ambivalencia implica la inserción de la historia en el texto y del texto en la historia, es decir, aborda la relación entre el texto y el contexto.

Kristeva no caracteriza la estructura, la forma, la función y el significado como rasgos inmanentes del discurso, sino como resultados de un proceso dinámico de producción y recepción de aquel. Este proceso no está centrado en el evento del habla, sino que se articula sobre la base de la conexión con otros segmentos del discurso. Las relaciones intertextuales entre un texto particular y uno anterior desempeñan un rol crucial para moldear la forma, la función, la estructura y el significado del discurso ${ }^{13}$. En otras palabras:

\footnotetext{
${ }^{9}$ J. Kristeva: "Bajtín...", p. 2.

${ }^{10}$ Kristeva señala la preparación de un libro sobre los "géneros del discurso". Aun cuando, al parecer, no estaba tan desarrollado el tema, Bajtín ya había denominado estos dos ejes "diálogo" y "ambivalencia".

${ }^{11}$ J. Kristeva: "Bajtín...", p. 3.

12 Ibid., p. 5.

${ }^{13}$ Charles Briggs, Richard Bauman: "Género, intertextualidad y poder social", Revista de Investigaciones Folklóricas, 11, 1996, pp. 78-108.
} 
Este enfoque intertextual sitúa la estructura literaria dentro de una estructura social que también es textual. Nada está dado fuera del DISCURSO, y un texto no es el reflejo de un "exterior" no textual, sino una práctica de escritura que inscribe $-\mathrm{y}$ está inscrita en- lo social así como en un campo intertextual, una malla de sistemas textuales ${ }^{14}$.

En síntesis, el concepto de intertextualidad propuesto por Kristeva otorga al funcionamiento de un texto en la historia y la sociedad, una dimensión tridimensional, compuesta por el sujeto que escribe, el destinatario y los otros textos. $\mathrm{Su}$ estructura, forma, función y significado son el resultado de un proceso de recepción y producción, es decir, consiste en una práctica dinámica y social.

Unas décadas más tarde, Gérard Genette revisó la categoría de intertextualidad propuesta por Kristeva y restringió su definición a "una relación de copresencia entre dos o más textos, es decir, eidéticamente y frecuentemente, como la presencia efectiva de un texto en otro" "A partir de esta nueva conceptualización, distingue tres formas en las que se manifiesta esta relación: la cita, el plagio y la alusión.

De esta manera, el debate que había surgido entre Kristeva y Bajtín y que intentaba encontrar respuestas al problema de las relaciones variadas e históricamente variables entre las obras literarias se limita a afirmar la existencia de intertextualidad cuando se reconoce un texto en otro posterior. Con ello, se excluyen de esta categoría de análisis todos aquellos textos en los que no se identifican sus antecesores. Para decirlo en palabras de Stephen Heath, la intertextualidad pasa a "usarse evaluativamente, distinguiendo los textos que intentan ocultar su naturaleza intertextual de aquellos que la reconocen y despliegan"16. Este segundo enfoque es el que han adoptado diversos musicólogos para analizar distintas relaciones “textuales" en música, limitando su conceptualización también en el campo de la música.

\section{La intertextualidad en música}

Uno de los primeros musicólogos que se dedicó al tema de la intertextualidad en música es Robert Hatten ${ }^{17}$. Desde un comienzo, el autor busca hallar en las obras musicales relaciones análogas a las existentes entre las obras literarias aunque propone una interpretación del concepto de intertextualidad más restringido al desarrollado en los estudios literarios, puesto que, tal como habían sido expresado por Kristeva -en su forma radical, como él la denomina-,

${ }^{14}$ Stephen Heath: "Intertextualidad", Diccionario de teoría crítica y estudios culturales, Michael Payne (comp.), Buenos Aires, Paidós, 2002, pp. 406-407; 406.

${ }^{15}$ Gérard Genette: Palimpsestos. La literatura en segundo grado, Madrid, Taurus, 1989, p. 10.

${ }^{16}$ S. Heath: "Intertextualidad"..., 406.

${ }^{17}$ R. Hatten: "El puesto...". 
esta conceptualización culmina en una red infinita de textos. Por ello, en el ámbito musical, define dos tipos de contextos -el del estilo y el de las estrategias- que le permiten "evitar la regresión infinita de la intertextualidad radical"18. Por un lado, el contexto del estilo consiste en la "competencia en el funcionamiento simbólico presupuesto por una obra musical"19. Por otro lado, el contexto de las estrategias comprende todas las manifestaciones particulares de las posibilidades dentro de un estilo. Las estrategias "afirman la individualidad de una obra al mismo tiempo que dependen de un estilo para su inteligibilidad" 20 . Estos dos contextos son, para Hatten, filtros mediante los cuales "extraemos relaciones pertinentes de innumerables relaciones concebibles, tanto intratextuales como intertextuales" 21 .

Hatten señala que el uso de patrones de estilos preexistentes adquiere un estatus intertextual siempre que exista un "uso conspicuo" de ellos. Sin embargo, no está explicitado quién posee la competencia para advertir ese uso: si el compositor, el intérprete o el oyente. En otras palabras, los sujetos se han tornado invisibles en este análisis y así, la intertextualidad habría de ser característica inmanente de la obra en tanto objeto y distinto de los sujetos intervinientes. Las ejemplificaciones que ofrece el autor en este artículo intentan mostrar claramente cuáles han sido las intenciones de los compositores al introducir referencias intertextuales en sus obras. Sobre esta cuestión me referiré en breve a raíz del tratamiento que otros musicólogos han hecho de este tema.

Otro de los estudiosos que se ha dedicado al tema es Omar Corrado, quien se ha referido a la cuestión identificando dos tipos de intertextualidad en música: intrasemiótica e intersemiótica. Según Corrado, la primera comprende "los hechos producidos con medios provenientes exclusivamente de las propiedades del lenguaje" 22 , y la segunda remite a "los fenómenos derivados de relaciones con otros discursos" ${ }^{23}$, tales como el texto, la imagen, el teatro. El autor se dedica a la cita como ejemplo intertextual en el que reconoce, a su vez, varios tipos. De su análisis y sus ejemplos se desprende el interés por las marcas culturales que presiden la recepción de las citas, y en este sentido concluye: "La cita inscribe una referencia tan fuerte que sustrae al discurso de la abstracción estructural para contextualizarlo, remitirlo a un espacio que convoca la complicidad de quienes se reconocen en el paradigma cultural desde el que se produce y se escucha" 24 .

\footnotetext{
${ }^{18}$ Ibid., p. 2.

${ }^{19}$ Ibid.

${ }^{20}$ Ibid.

${ }^{21}$ Ibid., p. 3.

22 O. Corrado: "Posibilidades intertextuales...", p. 34.

${ }^{23}$ Ibid., p. 34.

${ }^{24}$ Ibid., p. 49
} 
Otros dos autores que se han dedicado al problema de la intertextualidad en música han sido Rubén López Cano ${ }^{25}$ y Mark Spicer ${ }^{26}$. El primero se vale de varios ejemplos de música popular para establecer cinco tipos de intertextualidad en música, entendidas como referencias musicales a otras piezas que, según el grado de abstracción de las remisiones, denomina cita, parodia, transformación de un original, tópico y alusión. Esta clasificación está en consonancia con la propuesta por Genette en los estudios literarios. Por su parte, Spicer también realiza el análisis de obras de música popular apelando al concepto de intertextualidad, en este caso, escoge tres canciones de John Lennon. Llama la atención en ambos trabajos la coincidencia por buscar el sentido que tendrían las citas usadas para los compositores de esas obras, sin advertir el problema de la semanticidad de la música, y casualmente, los dos autores coinciden en el mismo ejemplo: "All you need is love", de The Beatle ${ }^{27}$. En él, ambos identifican una cita de "La Marseillaise" en los tres compases iniciales. Ahora bien, mientras que para Spicer esta cita es totalmente apropiada para la emisión OurWorld ${ }^{28}$, ya que sirve como señal internacional del mensaje universal de la canción ${ }^{29}$ y marca la quintaesencia francesa para evocar la atmósfera multinacional (junto con otras citas que aparecen en la canción), de acuerdo con el tema de esa ocasión ${ }^{30}$, para López Cano, "el himno francés puede estar relacionado con el arquetipo francés del "amour"”31.

Es evidente que aun cuando la competencia del oyente permita reconocer una cita en una obra (como caso de intertextualidad), dificilmente esta habilidad será suficiente para dar una explicación de la intención del compositor al haberla introducido. Más aún, tal como profesaba Kristeva, la intertextualidad no es un texto reflejo de un "exterior" textual, sino que ella consiste en una práctica que inscribe lo social en una red de sistemas textuales.

En el año 2018, López Cano retomó su análisis sobre intertextualidad y en esa oportunidad su definición fue "la habilidad cognitiva para detectar vínculos y semejanzas entre dos o más piezas que realiza un oyente desde sus competencias aurales, independientemente de las intenciones de los creadores de esas

\footnotetext{
${ }^{25}$ R. López Cano: "Más allá de la intertextualidad..." y R. López Cano: "Música e intertextualidad...".

${ }^{26}$ M. Spicer: "Strategic Intertextuality...".

${ }^{27}$ Ibid., p. 354: "Lennon and McCartney made an agreement when they were teenagers that, as long as they remained in a group together, all of their songs were to be credited as collaborations. Copyright restrictions continue to impose this stipulation even today, despite the fact that the majority of their Beatles songs were for the most part composed individually".

28 "All you need is love" fue compuesta por The Beatles para participar del evento One World. Este fue la primera producción televisiva internacional satelital en vivo, transmitida el 25-6-1967.

${ }^{29}$ M. Spicer: "Strategic...", p. 357: "Yet the instant familiarity of the tune is entirely appropriate here, since it is made to serve as a kind of international signpost leading the way into the universal message of 'All you need is love".

${ }^{30}$ Ibid., p. 359.

${ }^{31}$ R. López Cano: "Música e intertextualidad...", pp. 3-4.
} 
músicas"32. En otras palabras, a diferencia de su texto anterior, el acento está puesto en el lugar competente del oyente más que en rastrear intenciones de los compositores o intérpretes, aunque todos sus ejemplos remiten al lenguaje musical.

En síntesis, es claro que los análisis hasta aquí reseñados hacen hincapié en el "texto" musical. Han procurado examinar armonías, melodías, ritmos, estilos para poder establecer esas relaciones intertextuales. A continuación, exponemos una propuesta sobre intertextualidad más abarcadora y una conceptualización de la música en tanto práctica que permitirá un análisis más amplio de los ejemplos elegidos.

\section{Una conceptualización alternativa}

En el campo de los estudios sobre los medios de comunicación, John Fiske propuso una idea de intertextualidad que, a diferencia de las expuestas en el ámbito de la musicología, es menos restringida. Según este autor, la intertextualidad no necesariamente toma la forma de alusiones de un texto a otro - para lo cual sería necesario que los lectores estuvieran familiarizados con textos específicos-, porque la intertextualidad "existe más bien en el espacio entre textos" "33. En el análisis de su ejemplo sobre una canción paródica de Madon$\mathrm{na}^{34}$, Fiske señala que la intertextualidad refiere más bien a un reservorio de la propia cultura ${ }^{35}$ que, en su caso particular, es el banco de imágenes de estrellas cinematográficas cuyo estereotipo está asociado al star system norteamericano. En el argumento de Fiske, el espacio entre "textos" es el significado de "la rubia" de nuestra cultura. Los conocimientos intertextuales pre-orientan al lector activando algunos significados más que otros. Esta conceptualización comparte

${ }^{32}$ R. López Cano: Música dispersa, Apropiación, influencias, robos y remix en la era de la escucha digital, Barcelona, Musikeon books, 2018, p. 80.

${ }^{33}$ J. Fiske: "Television...", p. 108: "Intertextuality exists rather in the space between texts".

${ }^{34}$ John Fiske ilustra su concepto de intertextualidad con el siguiente ejemplo. J. Fiske: "Television...", p. 108: "Madonna's music video Material Girl provides us with a case in point: it is a parody of Marilyn Monroe's song and dance number 'Diamonds are a Girl's Best Friend' in the movie Gentlemen Prefer Blondes: such an allusion to a specific text is not an example of intertextuality for its effectiveness depends upon specific, not generalized, textual knowledge -a knowledge that, incidentally, many of Madonna's young girl fans in 1985 were unlikely to possess-. The video's intertextuality refers rather to our culture's image bank of the sexy blonde star who plays with men's desire for her and turns it to her advantage. It is an elusive image, similar to Barthes's notion of myth, to which Madonna and Marilyn Monroe contribute equally and from which they draw equally. The meanings of Material Girl depend upon its allusion to Gentlemen Prefer Blondes and upon its intertextuality with all texts that contribute to and draw upon the meaning of 'the blonde' in our culture".

${ }^{35}$ Charles Seeger utilizó la noción "banco de ideación" (bank of ideation) para referirse a las restricciones que limitan a los etnomusicólogos, y esto incluye, entre otras cosas, las historias individuales y los condicionamientos histórico-culturales. Kenneth Gourlay: "Towards a Reassessment of the Ethnomusicologist's Role", Ethnomusicology, 22, 1, 1978, pp. 1-35. 
con la desarrollada por Kristeva la condición de universalidad de la intertextualidad, pues, al fin y al cabo, todo texto remite a otro texto ${ }^{36}$.Y a diferencia de la propuesta de Genette y de quienes extrapolaron sus ideas a la música, no circunscribe la intertextualidad a la cita o a la alusión. Tampoco se involucra en el análisis de las intenciones de los compositores. Su propuesta, entonces, se acerca más a la explicación de Kristeva y Bajtín, quienes buscaban situar el texto en la historia y la sociedad.

La dinamización del texto -en un sentido amplio- que implica esta propuesta permite considerar la música de acuerdo a una conceptualización distinta a la abordada hasta aquí. Me refiero a la propuesta de Steven Feld ${ }^{37}$, quien la concibe como una práctica. Comprender la música en este sentido supone un modelo de análisis centrado en el "proceso de comunicación musical con un énfasis en el proceso de escucha más que en la partitura, el compositor, o el código per $\mathrm{se}^{\mathrm{\prime} 38}$. Su perspectiva rechaza el enfoque de Leonard Meyer por el énfasis que este autor pone en las dimensiones sintácticas de la música y por dejar de lado completamente las dinámicas de la performance, que están fuertemente vinculadas a sensaciones emotivas y a respuestas de la audiencia ${ }^{39}$. En su lugar, la propuesta de Feld enfatiza el carácter social de la comunicación musical. Es decir, hace hincapié en el oyente como ser situado social e históricamente y no solo como portador de órganos que recibe y responde a estímulos.

Siguiendo esta perspectiva, cada escucha es una "yuxtaposición, de hecho una implicación", de un objeto musical dialéctico (dialectical object) y un interlocutor situado. El carácter de las asociaciones es musical y extramusical. La interpretación requiere de un proceso activo (aunque puede ser inconsciente, intuitivo, banal). En otras palabras, el evento sonoro dirige la atención interpretativa a circunstancias de sentido a través de rasgos generales de naturaleza contextual y contextualizante. Tal como señala el autor:"Estos rasgos del modo en que nosotros escuchamos involucran forma-contenido y dialécticas musical-extramusicales" 40 . Estas últimas operan a través de diferentes "movimientos interpretativos" (interpretive moves) que suponen modelos de organización de nuestra experiencia a partir de yuxtaposiciones, interacciones o elecciones que se producen en el momento de captar diferentes "obje-

\footnotetext{
${ }^{36} \mathrm{Al}$ igual que Julia Kristeva, el autor distingue a una intertextualidad vertical y otra horizontal.

${ }^{37}$ Steven Feld: "Communication, music, and speech about music", Music Grooves, Chicago, Chicago University Press, 1994, pp. 77-95.

${ }^{38}$ Ibid., p. 83: "I will approach the process of musical communication with an emphasis on the listening process rather than the score, composer, or code per se".

${ }^{39} \mathrm{Ibid} .$, p. 84. Otra de las críticas señaladas a la teoría de Meyer es que "the framework does not account for varied meanings of the same piece to different listeners, or of the same piece to the single listener over time. One must, in other words, differentiate the syntactic features which might be said to arouse a listener, from the range and variety of musical feelings the listener may have in experiencing the piece".

${ }^{40} \mathrm{Ibid}$., p. 85: "This features of the way we listen involve form-content and musical-extramusical dialectics".
} 
tos simbólicos o performances" (symbolic objects or performances). Según Feld, los movimientos interpretativos constituyen diversas dimensiones de la acción comunicativa y pueden ser de cinco tipos: locacionales, categoriales, asociativos, reflexivos y evaluativos. Es decir, estos movimientos sitúan, esclarecen y dilucidan el proceso de reconocimiento que conlleva un evento musical.

En resumen, si consideramos la propuesta sobre intertextualidad de Fiske para el análisis de obras musicales y, al mismo tiempo, adoptamos la perspectiva de Feld, según la cual, los sujetos, en particular el oyente, ocupa un lugar central situado social e históricamente, es posible analizar la música y su relación con el contexto en un sentido más amplio. Siguiendo estos últimos lineamientos, propongo analizar dos casos de estudio en los que se incorporan al análisis del "texto" musical otros elementos constitutivos del evento, como son los instrumentos, las herramientas lingüísticas y las performances. Además de identificar relaciones intertextuales tanto en el sentido restringido de citas y alusiones, esta perspectiva en consonancia con lo propuesto por Fiske, posibilitará una lectura más amplia que comprenda el imaginario cultural de la audiencia y que, en definitiva, de una explicación más abarcadora de la inserción de la música en la historia.

\section{Les Luthiers}

Desde hace más de cincuenta años, el grupo argentino Les Luthiers ${ }^{41}$ ofrece espectáculos en los que se generan eventos humorístico-musicales, tanto en el transcurso de la ejecución de las obras como en sus intersticios, mediante la ejecución de obras propias, que remiten a géneros musicales pertenecientes a los ámbitos de las llamadas "música académica" y "música popular”. Esta particularidad, en la que se conjuga música y humor excede el enfoque de este trabajo $^{42}$, y permite que su obra también sea estudiada desde otras teorías ${ }^{43}$; sin

\footnotetext{
${ }^{41}$ Fundado en 1967 por Gerardo Masana, Les Luthiers tuvo varias formaciones. Después de algunas incorporaciones temporarias, el grupo se conformó con Gerardo Masana, Carlos López Puccio, Jorge Maronna, Marcos Mundstock, Carlos Nuñez Cortés, Daniel Rabinovich y Ernesto Acher (entre 1971 y 1973), luego con la muerte de Masana se redujo a sexteto (entre 1973 y 1986), más adelante se retiró Acher y solo fue un quinteto (1986-2015). Cuando en 2015 falleció Rabinovich y en 2017 se retiró Núñez Cortés, el grupo incorporó a dos nuevos integrantes, Horacio Turano y Martín O'Connor, y quedó compuesto como un sexteto hasta la actualidad.

${ }^{42}$ Un análisis exhaustivo de la relación entre música y humor y los diversos mecanismos humorísticos que establece Les Luthiers con su audiencia puede leerse en Juliana Guerrero: Música y humor en la obra de Les Luthiers (1967-2012), tesis doctoral, Universidad de Buenos Aires, 2013 (http://repositorio.filo.uba.ar/ bitstream/handle/filodigital/6036/uba_ffyl_t_2012_884724.pdf?sequence=1\&risAllowed=y).

${ }^{43}$ Por ejemplo, para un abordaje sobre la parodia política en la obra del grupo, confróntese J. Guerrero: "Feudalia, Ortega y Garcete: sobre la parodia política en la obra de Les Luthiers", Cuadernos de Música Iberoamericana, 28, 2015, pp. 173-192.
} 
embargo, la elección del caso busca descifrar el modo en que se establecen relaciones variadas entre obras o, extrapolando la idea de Kristeva y Bajtín, cómo se sitúa la música en la historia y la sociedad.

Recordemos que, si adoptamos la perspectiva de Feld, es posible afirmar que Les Luthiers establece con la audiencia una situación comunicativa que permite explicar la emergencia del humor como resultante de la articulación de distintos recursos, tales como, las presentaciones, los "instrumentos informales", los programas de mano, las herramientas lingüísticas y los géneros musicales. En este sentido, la obra de Les Luthiers se sitúa en la historia y la sociedad, como intentaré mostrar, a partir de diversos rasgos que exceden al lenguaje musical y en los que pueden identificarse prácticas intertextuales.

Uno de los recursos en los que se evidencia el modo en que la obra se sitúa en un contexto es la elección de la instrumentación. La característica identificativa del grupo es el empleo de "instrumentos informales" junto con la ejecución de instrumentos musicales convencionales. Los instrumentos de esta colección, que provocan efecto humorístico, comprenden 46 tipos, y además, de sus características musicales más específicas, son presentados de manera que establecen un lugar distinto al de los instrumentos convencionales. Es decir, sus nombres, sus características morfológicas y tímbricas, el tipo de ejecución que requieren y la relación que tienen con las obras en las que se los ejecuta funcionan de distinta manera que los instrumentos convencionales. De ahí que todos esos elementos sean significativos en la obra en cuestión para poder situarla cultural y socialmente, y comprender, en definitiva, cuáles son las expectativas a las que apela el grupo para generar el humor.

A continuación propongo ilustrar con más detalles algunos de estos instrumentos. Por ejemplo, el nombre de la Máquina de tocar o Dactilófono hace referencia a uno de los elementos con los que está compuesto el instrumento ${ }^{44}$. Su ejecución se realiza a través de la percusión de las teclas, que evoca un sonido similar a la de un xilófono. Por este modo de ejecución, el nombre y su morfología, el público observa cómo el músico "escribe a máquina”, mientras oye la música producida por el Dactilófono. Es importante recordar que en 1967, cuando se creó el instrumento, las máquinas de escribir eran objetos muy comunes que se utilizaban en las actividades de las oficinas. En particular, para crear el primer ejemplar del Dactilófono, Gerardo Masana empleó una máquina

${ }^{44}$ Está construido a partir de un armazón de una antigua máquina de escribir a la que se le han insertado tubos metálicos de distintas alturas en el lugar que habitualmente ocupa el carro. El mecanismo de las teclas se ha invertido y con ello se logra un movimiento divergente al presionar cada tecla, en lugar de que cada una converja en el centro, tal como es necesario en el uso convencional de la máquina. Cada tecla acciona un martillo que percute un tubo, logrando una escala cromática de dos octavas completas y sus sonidos son amplificados con un micrófono. 
Underwood, que pertenecía al estudio de abogados del padre de Daniel Rabinovich, integrante del grupo que por esos años estudiaba también abogacía y se recibió luego como escribano ${ }^{45}$. En otras palabras, el uso de la máquina de escribir como parte del Dactilófono genera lo que Feld denomina un movimiento interpretativo asociativo. Es decir, el público reconoce sobre el escenario un elemento que está recontextualizado y transformado ahora en instrumento musical.Además, ocurre con la mayoría de estos instrumentos informales que se producen movimientos interpretativos locacionales, que son aquellos que no permiten identificar parecidos y diferencias con otros elementos de referencia.

Por su parte, la Gaita de cámara remite en su nombre a un instrumento convencional (la gaita) y a un elemento con el que está construido ad hoc y que se utiliza para tales fines ${ }^{46}$. La gaita de Les Luthiers amplía exageradamente el odre o saco en el que se almacena el aire y ello hace que su presencia en el escenario, además, provoque extrañeza por las dimensiones que posee. Este instrumento se ejecuta en dos obras del grupo cuyos argumentos remiten a su presencia en el escenario. La primera obra hace referencia a un acto partidario en el que el candidato aparece parado sobre una escalera detrás del instrumento para remarcar la altura del reservorio de aire utili-

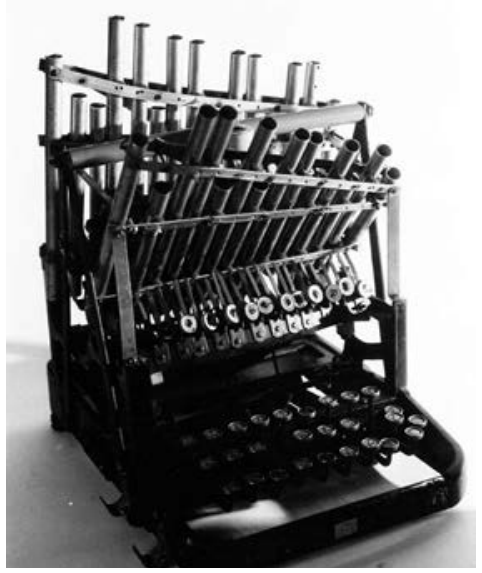

Máquina de tocar o Dactilófono ${ }^{47}$. zado y la segunda obra presenta los instrumentos más grandes de Les Luthiers en una competencia que tiene uno de los personajes con otro. En esa contienda, la Gaita de cámara es el último y más grande de los instrumentos ejecutados. De esta manera, la morfología del instrumento, que en la música "académica" no tendría relevancia con respecto a las obras en las que se ejecuta, aquí cobra un sentido constitutivo del tema de las obras musicales.

45 Sebastián Masana: Gerardo Masana y la fundación de Les Luthiers, Buenos Aires, Norma, 2005, pp. 148-149.

${ }^{46}$ Este instrumento informal está compuesto por una cámara de tractor que funciona como el reservorio de aire de una gaita. Mediante mangueras plásticas, están conectados a la cámara tres instrumentos: el Clamaneus (instrumento informal), el Glamocot (instrumento informal) y una melódica (originalmente, en el lugar de esta, el grupo había conectado un orlo). Estos instrumentos que son ejecutados simultáneamente por tres integrantes, pueden también ejecutarse de manera independiente. El aire de la cámara de tractor es la fuente para que cada uno de ellos funcione. Cada ejecutante controla, mediante un pedal, la entrada de la columna de aire en cada instrumento.

${ }^{47}$ Fuente: página oficial de Les Luthiers, http://www.lesluthiers.com/instrumentos-detalle.php?vi$\mathrm{d}=35$ \& $\sin s=3$. 


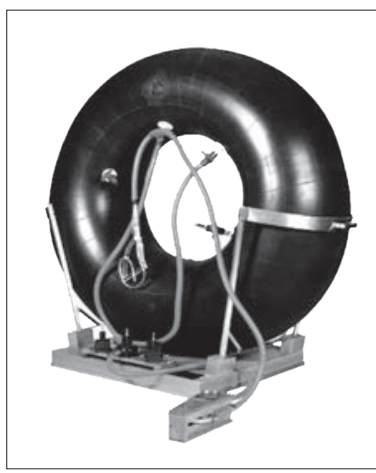

Gaita de cámara ${ }^{48}$.

Un instrumento en el que sorprende su tímbrica por la semejanza al siku tradicional es el Tubófono silicónico cromático o Flauta Bun$\operatorname{sen}^{48}$. Este nombre alternativo del instrumento, Flauta Bunsen, establece un juego entre la denominación general "flauta" y el nombre del químico alemán Robert Wilhelm Bunsen, inventor del mechero que lleva su nombre. Su parecido con una flauta de Pan es el movimiento interpretativo más evidente. La inserción de este instrumento en el mundo del grupo remite a la historia de su creador, Carlos Núñez Cortés. Este integrante del grupo estudiaba por aquel entonces Química y recuerda la siguiente anécdota: "En la época en que comenzamos a preparar la Cantata Modatón, yo llegaba de la facultad de Ciencias Exactas con algunos tubos de ensayo, los colocaba en un portatubos y les ponía agua. Luego los soplaba hasta darles la afinación correcta. La primera versión del tubófono fue hídrica"49.

Esta relación con la historia de uno de los integrantes del grupo da cuenta de su aparición dentro de la colección de instrumentos. Es impor-

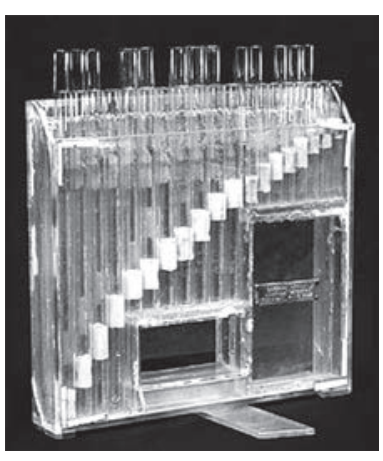

Tubófono silicónico cromático ${ }^{51}$. tante recordar que Les Luthiers comenzó como un grupo amateur que reunió a algunos integrantes de un coro universitario y que a partir de la propuesta de Gerardo Masana de componer obras cómicas fueron incorporando, además, estos instrumentos informales. El profesionalismo del grupo permitió que la colección aumentara considerablemente y que la sofisticación de los mismos fuera cada vez más grande, aunque ya desde el comienzo surgieron ejemplares ingeniosos y con una afinación precisa como el Tubófono silicónico cromático.

${ }^{48}$ Se trata de un aerófono constituido por 31 tubos de ensayo de vidrio que comúnmente se utilizan en procedimientos de biología y química. Todos ellos están sostenidos en una estructura de acrílico que permite ordenarlos en dos filas, tal como ocurre en la flauta de Pan, zampoña o siku; aunque a diferencia de estos, la distribución de los tubos imita la organización de las teclas blancas y negras del piano. La afinación cromática se obtiene con la introducción en cada tubo de un tapón de silicona, material que es explícitamente mencionado en su nombre.

${ }^{49}$ S. Masana: Gerardo Masana y la..., Buenos Aires, Norma, 2005, p. 147

${ }^{50}$ Fuente: página oficial de Les Luthiers, http://www.lesluthiers.com/instrumentos-detalle.php?vi$\mathrm{d}=25$ \& ins $=2$.

${ }^{51}$ Fuente: página oficial de Les Luthiers, http://www.lesluthiers.com/instrumentos-detalle.php?vi$\mathrm{d}=31$ \&ins $=2$. 
La Desafinaducha es uno de los instrumentos informales en el que su morfología evoca un elemento lejano del mundo musical ${ }^{52}$. La visualización del agua por las aspas del instrumento y su descarga en la pileta inferior remite indiscutiblemente al momento del aseo y al lugar del baño. En la única obra que aparece, "Loas al cuarto de baño" (obra sanitaria), este instrumento se ejecuta junto con el Nomeolbídet, el Calephone y la Lira de asiento, otros tres instrumentos informales, y todos juntos remedan la práctica habitual que una persona lleva adelante cotidianamente en ese espacio doméstico. Además, de su morfología, la intertextualidad está dada también en su tímbrica, ya que el glissando evoca sonidos extraños para las expectativas que el oyente puede tener de una obra de cuarteto. La presencia sobre el escenario de los instrumentos informales mencionados y su relación con otros artefactos de uso cotidiano acentúan también el fenómeno de recontextualización de la parodia, que se produce a partir de movimientos interpretativos reflexivos.

Como ilustran estos casos, los nombres de los instrumentos informales remiten a elementos que los componen, los cuales habitualmente no son partes de instrumentos musicales aunque algunos de sus mecanismos son compartidos con instrumentos musicales convencionales. Esta relación de los instrumentos informales con otros y con objetos de la vida cotidiana provoca un efecto humorístico sobre el escenario. La audiencia advierte su presencia, se sorprende y en varias ocasiones, el extrañamiento genera risa. Además de favorecer estos efectos humorísticos, las relaciones intertextuales generadas en la construcción y ejecución de los instrumentos contribuyen al mismo tiempo a la práctica paródica de los mismos.

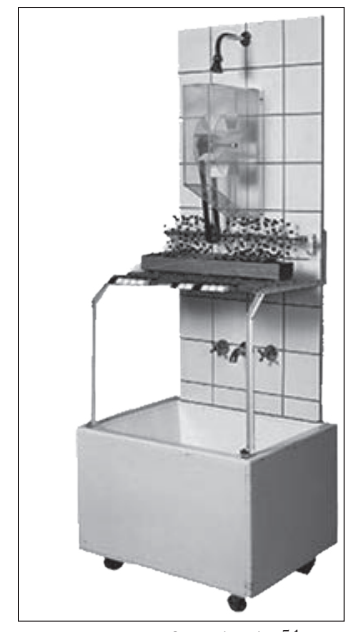

La Desafinaducha ${ }^{51}$.

\footnotetext{
${ }^{52}$ Este instrumento está construido imitando el funcionamiento de una ducha de baño. Su mecanismo es muy complejo. El agua que sale de ella agita unas aspas ubicadas al frente y, a través de una polea, se pone en movimiento un eje en el que están colocados unos pequeños martillos de acrílico, que percuten las placas de un metalofón. Este se encuentra cubierto por una caja de resonancia de acrílico y posee un micrófono de contacto para amplificar el sonido. Mediante una botonera, el ejecutante mueve las placas para que puedan ser percutidas. La cantidad de martillos y la velocidad con la que se mueven circularmente logran un efecto de trémolo sobre las placas. En su parte inferior, la Desafinaducha posee un receptáculo donde cae el agua proveniente de la canilla. El agua es recuperada por una bomba aspirante impelente que la recicla, enviándola por una tubería posterior nuevamente a la parte superior. El instrumento tiene dos réplicas de canillas y grifo que el músico simula abrir cuando pone en funcionamiento el instrumento, aunque en realidad la bomba se enciende con un interruptor colocado en la parte trasera.

${ }_{53}$ Fuente: página oficial de Les Luthiers, http://www.lesluthiers.com/instrumentos-detalle.php?vi$\mathrm{d}=36$ \& \&ins $=3$.
} 
Teniendo en cuenta la perspectiva de Fiske, la intertextualidad se verifica también en el nivel lingüístico. En este sentido, el Luthier Carlos Núñez Cortés ha señalado unos cuantos ejemplos de títulos de obras que parafrasean obras de compositores en su libro Los juegos de Mastropiero. Por ejemplo, "El alegre cazador que vuelve a su casa con un fuerte dolor acá", "es una paráfrasis del título de una pequeña obra para piano del Álbum de la juventud de Schumann: "El alegre campesino que regresa del trabajo" ${ }^{54}$. La "Romanza escocesa sin palabras" es "paráfrasis de una obra para piano de Félix Mendelssohn: las 48 Romanzas sin palabras, escritas por el compositor a lo largo de dos décadas" 55 . "Teresa y el oso" hace referencia al cuento orquestal "Pedro y el lobo" de Serguei Prokófiev y "Romance del joven conde, la sirena y el pájaro cu-cú.Y la oveja" es paráfrasis del Romance del Conde Olinos ${ }^{56}$. Estas alusiones son, en sentido estricto, ejemplos de intertextualidad de algunos de los nombres de las obras con otras composiciones musicales, generalmente conocidas por el público de Les Luthiers.

Sin embargo, las alusiones no son los únicos ejemplos de intertextualidad lingüística, sino que también se advierte en algunas de las letras de las obras un sentido menos restringido. Sus letras remiten tanto a obras anteriores puntuales como, en el sentido que le da a Fiske, al banco de imágenes que puede poseer el destinatario. Un ejemplo del primer caso, puede ser la estrofa de "Si no fuera santiagueño", la cual introduce una cita que remite a la chacarera doble "Añoranzas", de Julio Argentino Jeréz. Comienza con el mismo verso pero concluye con un sinsentido ${ }^{57}$. En cambio, un ejemplo de letras que remitan a una intertextualidad -como Fiske denomina- "entre textos" es "Dilema de amor" (cumbia epistemológica), obra compuesta por el grupo en el año 2009 para el espectáculo Lutherapia ${ }^{58}$. Tal como acostumbra el grupo, la obra es antecedida por una presentación, en este caso, como parte del guión del espectáculo, en el que uno de los integrantes explica al público que su compositor apócrifo, Johann Sebastian Mastropiero, la escribió por encargo de la Universidad de La Sorbonne pero que no tuvo mucho éxito en ese lugar sino en un ambiente popular.

Como es posible que la audiencia de Les Luthiers sepa, el género musical cumbia podría incluirse, en América Latina en general y, particularmente, en Argentina, como un género de música popular, consumido habitualmente

${ }^{54}$ Carlos Núñez Cortés: Los juegos de Mastropiero, Buenos Aires, Emecé, 2007, p. 284.

${ }^{55}$ Ibid., p. 285.

${ }^{56}$ Ibid., p. 286.

${ }^{57}$ La letra de "Añoranzas" es: "Cuando salí de Santiago / todo el camino lloré / lloré sin saber por qué, / pero sí les aseguro / que mi corazón es duro / pero aquel día aflojé". "Si no fuera Santiagueño" dice: "Cuando salí de Santiago / todo el camino he llorado / lloré porque había dejado / todo el camino mojado".

${ }^{58}$ Una versión de esta obra puede verse en el canal de Youtube del grupo: https://www.youtube.com/ watch?v=-Ucpbj5QZK0 (consulta 10-12-2018). 
por sectores de clase económica baja, muchas veces marginalizados y estigmatizados. Este género musical posee una temática amatoria cuyas letras explicitan relaciones amorosas, deseos sexuales y frustraciones afectivas.

En el caso de "Dilema de amor", la historia que narra la letra trata de un joven que se enamora de una estudiante de filosofia y a partir de esa relación mantiene un diálogo con sus compañeros. Mientras que el protagonista da cuenta de su "dilema" filosófico puesto que la mujer que conoció no comparte su pensamiento teórico, sus compañeros confunden la lista de filósofos famosos que el protagonista enumera con posibles interesados en la estudiante, desconocen los planteos que el protagonista hace y solo piensan en esa relación como acto sexual. A nivel lingüístico, la "epistemología" se emplea como eufemismo de la relación sexual ${ }^{59}$. Un recurso que utiliza Les Luthiers para aumentar el doble sentido que se le otorga al término "epistemología" en el transcurso de la letra es su uso como sustantivo (epistemología, epistemólogas) tanto como verbo ("epistemologando", "se lo epistemologaba"). En este caso, la práctica intertextual que propone Les Luthiers a nivel lingüístico no espera que el público reconozca la letra de ninguna cumbia en particular, esto es, no recurre a alusiones o citas, en cambio, es suficiente tener una idea general -un banco de ideación- de la cumbia, especialmente en Argentina, para advertir que el grupo compone una letra cuya expectativa es la explicitación de una relación carnal y al contrario emplea un campo semántico relacionado con un pensamiento académico y erudito y lo ridiculiza. Extrapolando la idea de Fiske, la intertextualidad, en este caso y en la mayoría de las obras de Les Luthiers, está relacionada con bancos de imágenes compartidos socialmente entre el grupo y su público más que por relaciones estrechas como pueden ser ejemplos de intertextualidad más estricta. De allí que la letra de la obra repase una nómina de filósofos (Kierkegaard, Sartre, Marcuse, Spengler, Erasmo de Rotterdam, Wittgenstein) para enfatizar el estudio universitario y se contraponga a través de distintos recursos literarios como los dobles sentidos, enumeración y homofonía.

Ahora bien, en este ejemplo de Les Luthiers, la práctica intertextual no se produce solamente a nivel lingüístico. Su performance ${ }^{60}$ también está atravesada por dicha práctica. Como sucede con todos los géneros musicales, la instrumentación puede ser concebida como una de las "reglas" que lo confor$\operatorname{man}^{61}$. En el caso de la cumbia es habitual que, además de alguna guitarra

\footnotetext{
${ }^{59}$ Se ha reproducido la letra de la canción en el apéndice final.

${ }^{60}$ El concepto de performance ha sido abordado desde distintas disciplinas. Una lectura de algunas de esas teorías en la obra de Les Luthiers puede verse en J. Guerrero "Las presentaciones de Les Luthiers como performances”, Telondefondo. Revista de Teoría y Crítica Teatral, 19, 2014 (http://telondefondo.org, consulta 10-10-2016).

${ }^{61}$ La idea de reglas de género fue propuesta en los estudios de música popular por Franco Fabbri: "A Theory of Musical Genres: Two Applications", Popular Music Perspectives, Philip Tagg, D. Horn (eds.), Göteborg-Exeter, IASPM, 1982, pp. 52-81. También J. Guerrero: "El género musical en la música popular:
} 
y bajo eléctricos, los grupos ejecuten un keytar y un güiro entre los instrumentos de percusión. De allí que en "Dilema de amor" Les Luthiers plantee el vínculo de esta obra con el género cumbia a través de la ejecución de un bajo eléctrico, un keytar y una pista de MIDI que completa la percusión y algunas líneas melódicas. Además de la instrumentación, el posicionamiento del grupo en el escenario es también importante. Al igual que los músicos de cumbia, Les Luthiers se presenta frente al público y mientras cantan, se mueven con una coreografía acotada a la que le incorporan gestos que acentúan partes de la letra. El baile que propone evoca al conocido en Argentina por aquellos músicos que ofrecen cumbia. Además, para remarcar el estereotipo del "filósofo", Carlos Núñez Cortés, el integrante que asume ese personaje, lleva puestos unos llamativos anteojos.

En su performance la relación de Les Luthiers con su audiencia se verifica no solo con el modo en que el público espera escuchar una cumbia, sino también con las marcas coreográficas, gestuales, de vestuario (el grupo se presenta en sus funciones vestidos de esmoquin) y puesta en escena, que se inscriben y están inscriptos -como sostenía Kristeva en el mundo literario- en lo social y dan sentido a esa música. Así, el complejo entramado que supone establecer relaciones intertextuales en una práctica musical excede las referencias del lenguaje y se verifican también en todos los otros elementos que completan esta situación comunicativa.

La intertextualidad en el nivel de la performance es evidente, asimismo, en el caso del "Concierto Mpkstroff" 62 . En esta obra que evoca un concierto de "música académica", Marcos Mundstock, a cargo del timbal y los platillos, intenta auxiliar a su compañero sin interrumpir la obra y Carlos Núñez Cortés, que ejecuta el piano, realiza una serie de contorsiones y movimientos que exageran los gestos propios de un músico concertista y hasta termina cayéndose de la banqueta del piano. En este caso, la gestualidad exagerada, los movimientos excesivamente marcados y grotescos y las respuestas de cada uno de los músicos remiten al comportamiento de los músicos de conciertos de los que la audiencia espera movimientos acotados, reglas establecidas y patrones consensuados. La ejecución del "Concierto Mpkstroff”, en términos gestuales y corporales, solo puede comprenderse si se recurre a un banco de imágenes de otros conciertos académicos.

Por último, es posible identificar en la obra de Les Luthiers ese tipo de intertextualidad más restringida que es la cita textual de una melodía y a la que han hecho referencia los trabajos musicológicos arriba mencionados. Por

\footnotetext{
algunos problemas para su caracterización", TRANS-Revista Transcultural de Música, 16, 2012 (http://www. sibetrans.com/trans/, consulta 10-1-2014).

${ }^{62}$ Esta obra fue estrenada en el espectáculo Recital 72 y existen varias versiones de esta obra. Puede considerarse para este análisis la siguiente versión: https://www.youtube.com/watch?v=Y3HzBU7EAis (consulta 18-12-2018).
} 
ejemplo, en otro trabajo ${ }^{63}$ me he referido a la inclusión paródica de un verso del "Feliz cumpleaños" en la obra "Canción a la independencia de Feudalia". En este caso, la incorporación de la famosa melodía se encuentra en el verso final de la última estrofa con el que el grupo remata la obra. Asimismo, hay otros casos de citas y alusiones. Tal es el caso de "Las majas del bergantín" (Zarzuela náutica), en la que se perciben fragmentos del intermedio de "La boda de Luis Alonso" de Gerónimo Giménez y del intermedio de "La leyenda del beso" de Reveriano Soutulloo y Juan Vert. Al igual que lo que ha ocurrido en los análisis musicológicos reseñados al principio de este trabajo, la identificación de citas y alusiones también son corrientes en una lista de discusión creada por los seguidores del grupo en la que ha circulado un catálogo que incluye diversos fragmentos dentro del centenar de obras de Les Luthiers y su relación con obras del canon musical "clásico" entre los que se encuentran, por ejemplo, Ludwig van Beethoven, Frédéric Chopin, Piotr Ilich Chaikovski, Wolfgang Amadeus Mozart, Georg Friedrich Händel y Karlheinz Stockhausen.

La extensa obra de Les Luthiers en sus más de cincuenta años de trayectoria permite advertir, si se considera su música como una práctica comunicativa que se activa cuando el grupo sube al escenario y establece con la audiencia una complicidad única, que su sentido poético desborda el "texto" musical para replicarse en otros elementos como son la instrumentación, las letras de sus canciones y sus puestas en escena entendidas como performances. Estos recursos se complementan, además, con otro de los mecanismos utilizados como práctica intertextual, como es el caso de la fusión de géneros. Para poder ejemplificarlo con mayor detalle, a continuación me referiré brevemente a otro grupo musical argentino que, al igual que Les Luthiers, incursionó en juegos compositivos de músicas "académicas" y "populares".

\section{La Banda Elástica}

Se trata de un grupo musical fundado en 1988 y disuelto en 1993, que reunió a ocho músicos argentinos que provenían del jazz ${ }^{64}$. El repertorio elegido abordaba "todo tipo de música, desde el jazz hasta el folclore, sin privarse del humor, tanto musical como gestual, y ciertamente sin dejar de

\footnotetext{
${ }^{63}$ J. Guerrero: "Feudalia, Ortega y Garcete...", pp. 173-192.

${ }^{64}$ Sus integrantes fueron: Carlos Costantini (trompeta, fluegelhorn, teclado, bajo, canto, composición y arreglos); Hugo Pierre (saxo alto y soprano, clarinete); Enrique Varela (saxo tenor y soprano, clarinete, canto); Ernesto Acher (trombón, saxo barítono, clarinete, clarinete bajo, corno, piano, canto, composición y arreglos); Jorge Navarro (piano, teclado, percusión, vibrafón, canto); Ricardo Lew (guitarras, bajo, percusión, composición y arreglos); Juan Amaral (bajo, guitarra, canto) y Enrique Roizner (batería, percusión). Su producción quedó registrada en tres discos.
} 
lado un cierto sabor jazzístico" "65. Esa diversidad de géneros musicales estaba ya en el nombre "banda", que hacía referencia (según su fundador Acher) a esa pretención de conformar una "bandita dixieland con variantes" 66 . Por otra parte, "elástica" remitía a la intención de presentar arreglos de obras provenientes del folclore, el tango y otros géneros populares.

Un ejemplo de esta elasticidad con la que ejecutaban la música es "Luna tucumana". Se trata de una zamba compuesta por Atahualpa Yupanqui e interpretada por el autor en la guitarra. Cuando La Banda Elástica propone ejecutar "Luna tucumana" fusiona elementos de distintos géneros, que no son todos del lenguaje musical sino que remiten a otras reglas de género. Mientras que en su versión original está ejecutada en $86 \mathrm{bpm}$ aproximadamente, el tempo de la versión del grupo de Acher se acelera a los 100 bpm, tal vez más cercano al jazz. Además, se reemplaza la guitarra de Yupanqui por saxos, piano y un set de percusión y en alguna actuación en vivo, incorporaron bajo eléctrico y teclados. De esta manera, si bien se respeta la melodía, se intercalan algunas improvisaciones, el acompañamiento de la percusión remite a géneros centroamericanos y la voz "¡adentro!", característica de algunos géneros folclóricos argentinos para indicar a los bailarines cuándo comenzar a bailar, se complementa con "isabor!" en un interludio improvisatorio que remite a esa fusión. Todos estos elementos generan, al decir de Feld, movimientos interpretativos que permiten establecer relaciones entre la obra original y el nuevo arreglo.

La estrofa que se canta no respeta la letra original y al final se oye a Acher decir "acolde", imitando la voz de un niño. Esta última intervención puede ser leída como alusión a un personaje que el propio Acher estableció en su paso por el grupo Les Luthiers. En 1980 se estrenó un espectáculo, que incluía una obra denominada "La gallina dijo eureka" (canción infantil). Allí Acher encarnaba un personaje infantil que se caracterizaba por no pronunciar correctamente algunas consonantes. Esa manera particular de hablar junto con el tono de voz que imita a un niño pequeño es la que repite Acher en esta obra de La Banda Elástica. Al igual que lo ocurrido en algunos de los ejemplos de Les Luthiers más arriba, la relación de la obra con su contexto permite identificar sentidos que exceden el lenguaje musical.

Los tangos “A Orlando Goñi” de Antonio Gobbi y "Flores negras" de Francisco de Caro tambien están arreglados con una orquestación propia del jazz. Si bien prima la fusión de géneros musicales, el grupo acentúa marcas propias del tango como el marcato de la mano izquierda del piano y, en el primer caso, algunos pasajes de la melodía en el registro más agudo del piano. Entre sus obras aparecen, además, algunas composiciones a manera de homenaje a mú-

${ }^{65}$ Una breve reseña de la historia del grupo se puede consultar en: http://ernestoacher.blogspot. com/2005/06/la-banda-elastica.html (consulta 8-12-2018).

${ }^{66}$ http://ernestoacher.blogspot.com/2005/06/la-banda-elastica.html (consulta 8-12-2018). 
sicos consagrados. Tales son los casos de "Homenaje al trío de Benny Goodman" y "Pequeño Gershwin ilustrado" que están compuestos por fragmentos de obras clásicas de jazz, como por ejemplo "If I had you" y "Avalon" en el primero, y "Rhapsody in blue", "Summertime", "Lady be good", "Bess, you is my woman now", en otros, en el segundo.

La intertextualidad en este segundo caso puede entenderse entonces como una práctica de la composición. La decisión del grupo de fusionar géneros musicales, ofrecer arreglos con instrumentaciones distintas a las ejecutadas en sus versiones originales y establecer así esas músicas en nuevos contextos está en concomitancia con aquella perspectiva de Bajtín de dinamización de producción y recepción de los textos, aquí entendidos en un sentido amplio. Extrapolando su propuesta, no se trata de concebir las obras como puntos fijos sino de un diálogo de varias "escrituras".

\section{Conclusiones}

Concebir la música como una práctica social, que no tiene asociados valores intrínsecos ni criterios universales sino que son los sujetos que la producen y consumen los que les atribuyen dichas características, permite interpretar y analizar una cultura solo en sus propios términos. Al igual que lo que señalaba Kristeva para la literatura, más que comprender la estructura, la forma, la función y el significado como rasgos inmanentes del discurso, estos son, por el contrario, resultados de un proceso dinámico de producción y recepción.

En los casos de la música de Les Luthiers y La Banda Elástica, el concepto de intertextualidad es central para poder identificar los juegos humorístico-musicales que propone el primer grupo, y la diversidad y fusión de géneros que ofrece el segundo. Estas estrategias apelan a la competencia de la audiencia y, con el público, establecen, así, una complicidad que inscribe sus músicas socialmente. Ello requiere de una actitud activa por parte del oyente, en la que interviene también su expectativa y su bagaje cultural. A diferencia de otros estudios musicológicos, este enfoque supone un modelo de análisis centrado en el proceso de comunicación musical. Esto significa hacer hincapié en el oyente como ser situado social e históricamente y no solo como portador de órganos que recibe y responde a estímulos.

En este marco, la intertextualidad puede ser concebida, tal como propuso Julia Kristeva, como esa práctica que da cuenta del proceso dinámico de producción y recepción de los textos literarios. En el caso de la música, para poder identificar esas relaciones, más que cerrar y restringir el concepto a una condición evaluativa de reconocimiento de músicas anteriores (fundamentalmente elementos del lenguaje musical tales como melodías, armonías, ritmos y estilos), he intentado mostrar cómo otros elementos del evento musical (gestos, corporalidad, instrumentación, letras, títulos y nombres de géneros, tímbricas, 
etcétera) pueden dar cuenta de la compleja trama en la que se encuentra tejida una obra musical. El reconocimiento y la identificación de esas relaciones no son solamente los correspondientes a citas o alusiones sino que apela, en definitiva, al reservorio que posee la audiencia de su propia cultura.

\section{Apéndice}

\section{Dilema de Amor (cumbia epistemológica)}

Estoy enamorado por fin me enamoré el sábado a la noche, en el baile la encontré.

Estaba vestida para enamorar sensual y atractiva y me miraba sin parar.

Si dos jóvenes se atraen ya nada los detiene; ustedes ya saben todo lo que viene.

Salimos a bailar; la miré, me miró, y el deseo fulminante los atrapó.

Y mientras se movía, ¡Qué fascinante! para impresionarme, ¡Qué sugerente! se puso a hablarme... ¡Qué excitante! ...de filosofía.

¡Qué interesante!

De inmediato reaccioné y ahí mismo en la pista... ¿Ahí mismo en la pista? ...la enfrenté y le pregunté si era aristotélica o tomista. La la la la la.

No paramos de bailar, nuestros labios se atraían y empezamos a hablar de epistemología.

Los jóvenes inventan palabras cada día se ve que ahora lo llaman "epistemología".

Qué bonito mi amor, qué bonito mi amor, hacer cada día, hacer cada día, juntitos los dos la epistemología.

Tocamos muchos temas de antropología... $\mathrm{y}$ entonces hicieron la epistemología.

Del estructuralismo, del rumbo del arte y el existencialismo: ¡de Kierkegaard a Sartre!

Ella sacudía

Ella sacudía su estructuralismo su estructuralismo y él hacía lo mismo con su antropología.

Y hablando de Marcuse de Spengler y Lacan llegamos a Erasmo de Rotterdam.

Los jóvenes se aman con tanto entusiasmo 
que solo con hablar

ya llegan al Erasmo.

Y fueron a la cama... ¡No! ¡No! ¡No!

El amor no solo es ir con alguien a la cama. ...también se puede hacer de pie o en la ventana.

Me dijo que leía

a Wittgenstein

y que la enloquecía

su epistemología.

Yo que tú me cuidaría, ya nombró como a doce, con cualquiera que conoce hace epistemología.

Yo le dije que ese tipo solo quería quitar lo metafísico de la filosofía.

No se puede estar amando metafísico no más... ...ni estar a cada rato epistemologando.

Me preguntó con cinismo si yo no concebía otra metodología que el materialismo.
Ella criticaba

tu metodología

pero tipo que veía

se lo epistemologaba.

¡Le dije que se fuera!

El pensamiento formalista

acaba en idealismo

subjetivo y atomista.

¡La mandaste a mudar,

la echaste sin piedad!

¡No se debe aceptar

la banalidad!

Ya encontraré a otra

con más afinidad

epistemólogas hay muchas

en la facultad

Nos has revelado

otra realidad

nos has señalado

el camino a la verdad.

Vamos a cambiar

Vamos a cambiar

esta vida vacía

esta vida vacía

vamos todos a estudiar

¡Epistemología!

Recibido: 28-2-2019

Aceptado: 13-7-2019 